Article

\title{
Structural Changes in Hippocampal Subfields in Patients with Continuous Remission of Drug-Naive Major Depressive Disorder
}

\author{
Asuka Katsuki ${ }^{1}$, Keita Watanabe ${ }^{2}$, LeHoa Nguyen ${ }^{1}$, Yuka Otsuka ${ }^{1}$, Ryohei Igata ${ }^{1}$, \\ Atsuko Ikenouchi ${ }^{1}$, Shingo Kakeda ${ }^{3}$ (D) , Yukunori Korogi ${ }^{2}$ and Reiji Yoshimura ${ }^{1, *}$ \\ 1 Department of Psychiatry, University of Occupational and Environmental Health, 1-1 Iseigaoka, \\ Yahatanishi-ku, Kitakyushu 807-8555, Japan; asuka-k@med.uoeh-h.ac.jp (A.K.); \\ leehoa2k4@med.uoeh-u.ac.jp (L.N.); yharada@med.uoeh-u.ac.jp (Y.O.); igataryouhei@gmail.com (R.I.); \\ atsuko-i@med.uoeh-u.ac.jp (A.I.) \\ 2 Department of Radiology, University of Occupational and Environmental Health, 1-1 Iseigaoka, \\ Yahatanishi-ku, Kitakyushu 807-8555, Japan; sapient@med.uoeh-u.ac.jp (K.W.); \\ ykorogi@med.uoeh-u.ac.jp (Y.K.) \\ 3 Department of Radiology, Hirosaki University Graduate School of Medicine, Hirosaki 036-8562, Japan; \\ kakeda@med.uoeh-u.ac.jp \\ * Correspondence: yoshi621@med.uoeh-u.ac.jp; Tel.: +81-936917253; Fax: +81-936924894
}

Received: 3 March 2020; Accepted: 22 April 2020; Published: 25 April 2020 updates

\begin{abstract}
Objective: Hippocampal volume is reduced in patients with major depressive disorder (MDD) compared with healthy controls. The hippocampus is a limbic structure that has a critical role in MDD. The aim of the present study was to investigate the changes in the volume of the hippocampus and its subfields in MDD patients who responded to antidepressants and subsequently were in continuous remission. Subjects and Methods: Eighteen patients who met the following criteria were enrolled in the present study: the DSM-IV-TR criteria for MDD, drug-naïve at least 8 weeks or more, scores on the 17-items of Hamilton Rating Scale for Depression (HAMD) of 14 points or more, and antidepressant treatment response within 8 weeks and continuous remission for at least 6 months. All participants underwent T1-weighted structural MRI and were treated with antidepressants for more than 8 weeks. We compared the volumes of the hippocampus, including its subfields, in responders at baseline to the volumes at 6 months. The volumes of the whole hippocampus and the hippocampal subfields were measured using FreeSurfer v6.0. Results: The volumes of the left cornu Ammonis (CA) $3(p=0.016)$ and the granule cell layer of the dentate gyrus (GC-DG) region $(p=0.021)$ were significantly increased after 6 months of treatment compared with those at baseline. Conclusions: Increases in volume was observed in MDD patients who were in remission for at least 6 months.
\end{abstract}

Keywords: brain morphology; major depressive disorder; hippocampus; cornu Ammonis; dentate gyrus; antidepressant

\section{Introduction}

Major depressive disorder (MDD) is a lifelong, episodic, prevalent and disabling mental disorder found in individuals worldwide. The cause of MDD is multifactorial, including genetic, neurobiological, and environmental factors, as well as their interactions. The hippocampus plays an important role in MDD. According to the reviewed literature, MDD is characterized by an altered structural network that encompasses reduced volumes of the orbitofrontal cortex(OFC), anterior cingulate, hippocampus, and striatum [1]. The anterior cingulate cortex, amygdala and hippocampus comprise 
an interconnected prefrontal neocortical and limbic network that is dysregulated in MDD. Modulation of this prefrontal-limbic network occurs primarily through the hypothalamus, basal ganglia and midbrain [2]. Structural abnormalities in the hippocampus are present in MDD. This region is considered to regulate behavioral and neuroendocrine responses to stress and can be damaged by excessive exposure to the stress-induced release of steroidal and inflammatory signaling molecules [3]. The hippocampus is a complex structure and is related to many emotional, memory, and cognitive functions. MDD is associated with a volume reduction in the hippocampus compared with healthy controls, a finding that has been relatively consistent across studies [4-6]. The structure of the hippocampus comprises 26 subfields (13 left and 13 right) with distinct morphologies [7,8].

Increased right hippocampal volumes have been found in female responders compared to nonresponders after 8 weeks of fluoxetine treatment among MDD patients [9]. On the other hand, treatment with escitalopram did not result in a change the hippocampal volume [10]. Maller et al. [11] determined that a larger hippocampal tail volume was positively related to clinical remission between patients who did and did not undergo remission to antidepressant medications in volume analyses of 12 hippocampal subfields. Cao et al. [12] found that ECT-induced volume increases in the cornua Ammonis (CAs), the dentate gyrus layer (GCL), the molecular layer (ML) and the subiculum by using a segmentation pipeline. Thus, it has not been elucidated whether treatment with antidepressants affects the hippocampal volume, and changes in hippocampal volume after recovery from MDD remain unclear. It remains unclear if hippocampal volume is reduced in hippocampus in MDD or if volume increases in remission. Volume reduction may be due to disease severity, duration, or recurrent nature of MDD, or to the age of onset.

To the best of the authors' knowledge, no previous reports have investigated the volume of hippocampal subfields after 6 months of continuous remission in MDD patients after treatment with antidepressants, therefore the aim of the present study was to investigate the changes in the volumes of the hippocampus and its subfields in MDD patients who responded to antidepressants and subsequently are in continuous remission.

\section{Results}

\subsection{Participants}

Eighteen participants responded to treatment with antidepressants, and none were relapsed within at least 6 months. We demonstrate the HAMD score trajectory of each case in Figure 1. The subfields of the hippocampus are shown in Figure 2a-c.

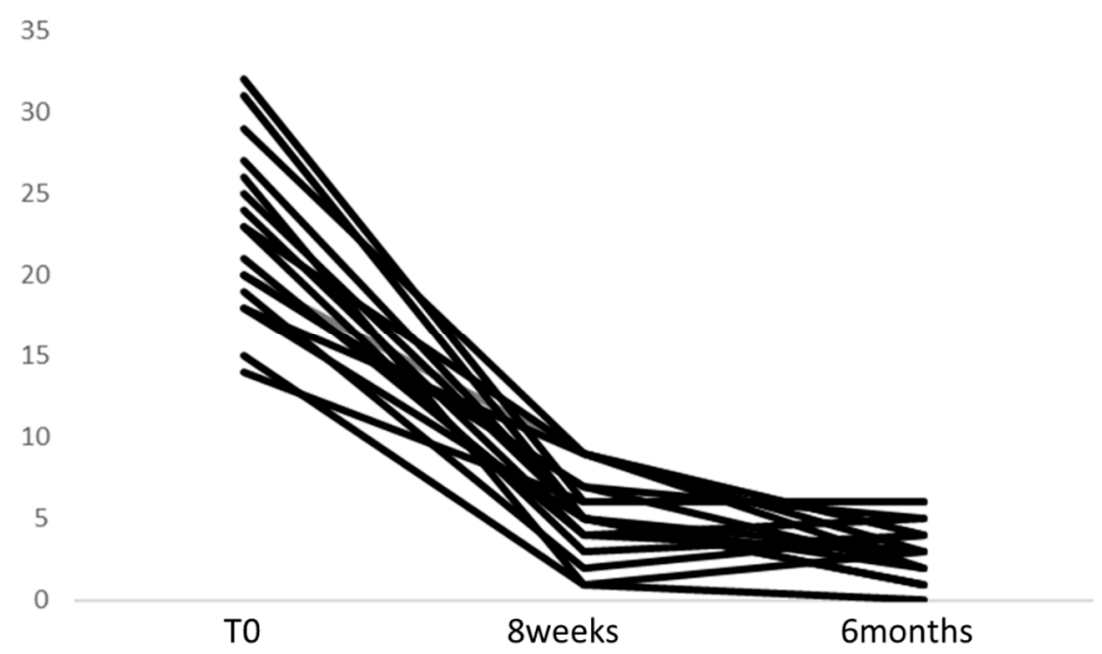

Figure 1. The HAMD score trajectory of each MDD case. Each line presents the change the HAMD score at baseline, 8 weeks, and 6 months after starting antidepressants. 
(a)

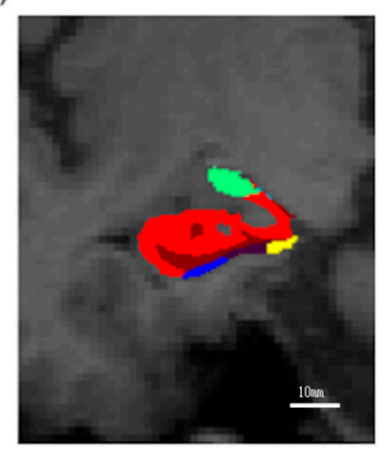

(b)

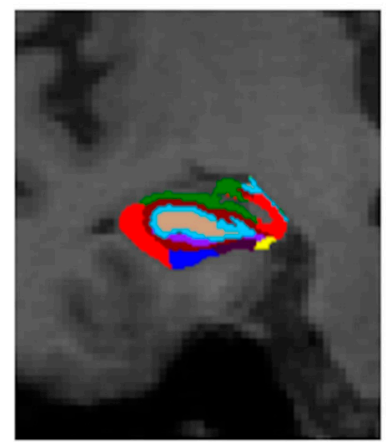

(c)

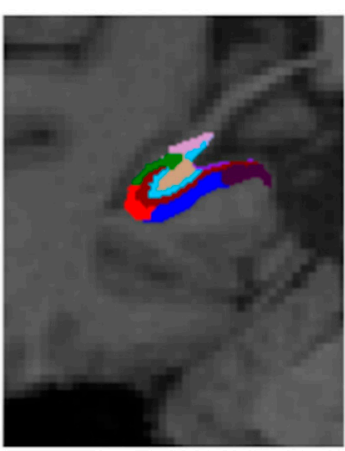

Figure 2. Representative subdivision of the hippocampal subfields. The mask of each region was overlaid on coronal T1-weighted images from anterior (a), middle (b), to posterior (c). Color classification: parasubiculum = yellow; presubiculum = black; subiculum = blue; cornu Ammonis (CA) 1 = red; CA3 = dark green; CA4 = brown; granule cell layer of the dentate gyrus (GC-DG) = sky blue; hippocampus-amygdala transition area (HATA) = green; fimbria = purple; molecular layer of the hippocampus $(\mathrm{HP})=$ dark brown; hippocampal fissure = dark purple; hippocampal tail = gray.

\subsection{Volume of Whole-Hippocampus}

No significant difference was found between the volume of whole hippocampus at baseline and six months after treatment initiation (Figure $3 a, b$, Table $1 \mathrm{a}, \mathrm{b}$ ).

\subsection{Volumes of Hippocampal Subfields}

A significant volume increase was found at 6 months in the molecular layer of hippocampus, the GC-MLDG, the CA3 (Figure 3a). We did not find a significant change in any other subfield volume at right (Figure $3 b)$.
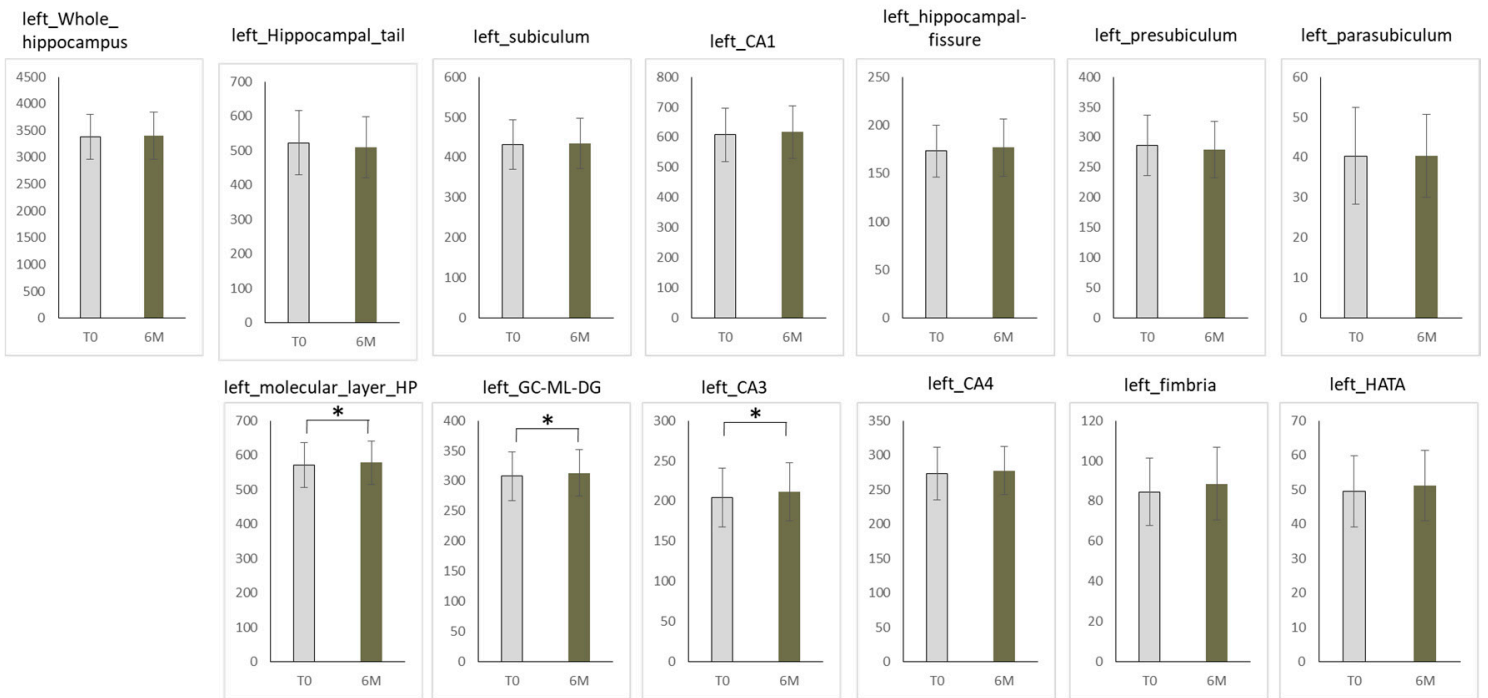

(a)

Figure 3. Cont. 

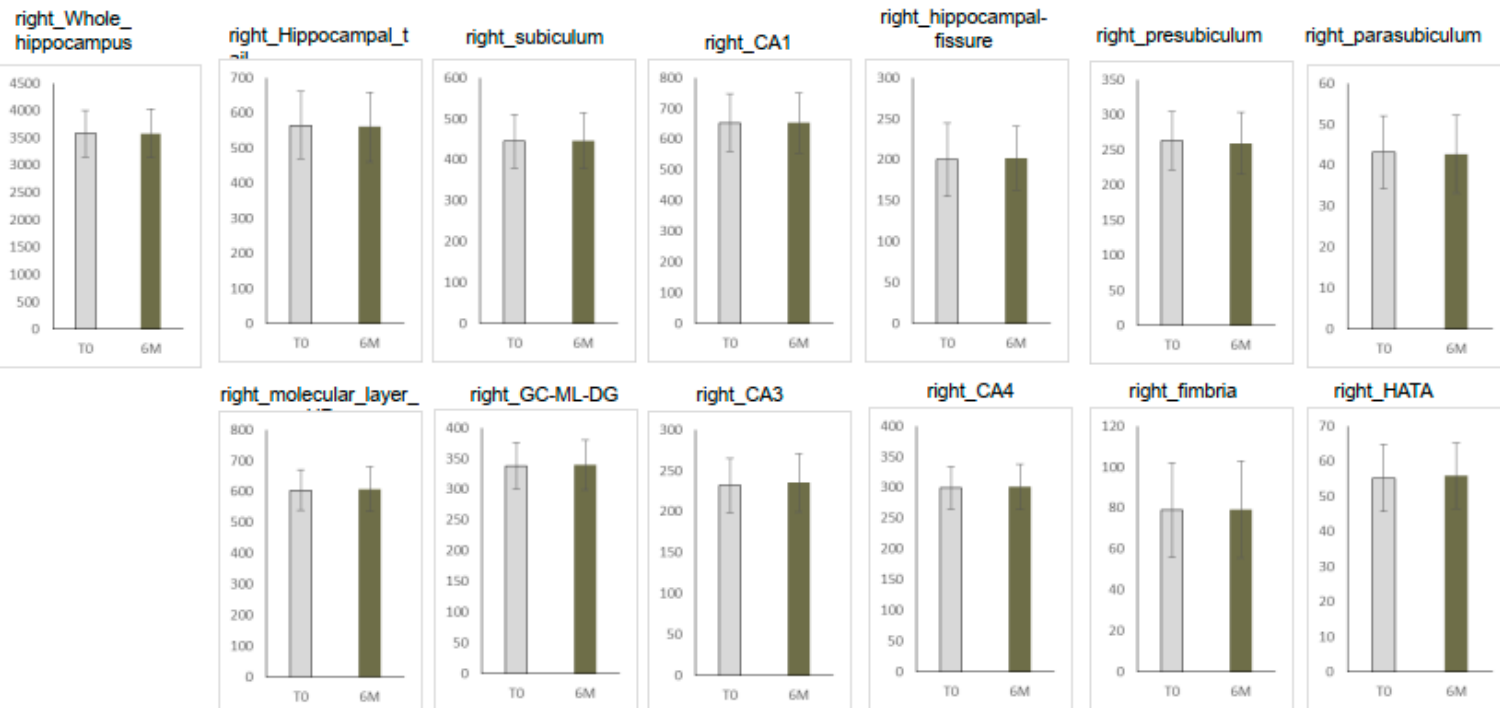

right_CA3

right_CA4
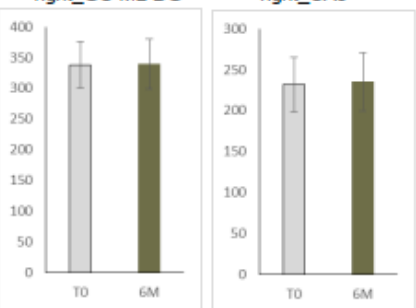

right_fimbria

right_HATA
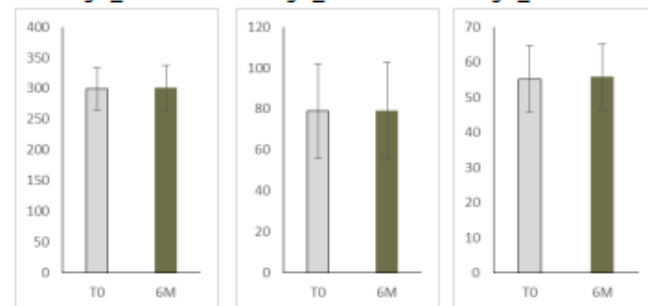

(b)

Figure 3. Subfield volume in hippocampus at left (a) and right (b). T0; baseline, 6M; after 6 months, Y-axis shows volume in hippocampus subfields $\left(\mathrm{mm}^{3}\right)$.Vertical bar means standard error (SEM).

Table 1. Volumes of Hippocampal Subfields at left (a), and right (b).

\begin{tabular}{|c|c|c|c|c|c|c|c|}
\hline (a) & & & & (b) & & & \\
\hline & T0 & $6 \mathrm{M}$ & & & T0 & $6 \mathrm{M}$ & \\
\hline \multirow[t]{2}{*}{$\mathrm{n}$} & 18 & 18 & & $\mathrm{n}$ & 18 & 18 & \\
\hline & $\begin{array}{c}\text { Mean } \pm \text { SD } \\
\left(\mathrm{mm}^{3}\right)\end{array}$ & $\begin{array}{c}\text { Mean } \pm \text { SD } \\
\left(\mathrm{mm}^{3}\right)\end{array}$ & $p$-value & & $\begin{array}{c}\text { Mean } \pm \text { SD } \\
\left(\mathrm{mm}^{3}\right)\end{array}$ & $\begin{array}{c}\text { Mean } \pm \text { SD } \\
\left(\mathrm{mm}^{3}\right)\end{array}$ & $p$-value \\
\hline left_Hippocampal_tail & $521.9 \pm 93.2$ & $509.7 \pm 88.8$ & 0.063 & right_Hippocampal_tail & $565.2 \pm 94.9$ & $560.3 \pm 98.6$ & 0.428 \\
\hline left_subiculum & $432.0 \pm 61.8$ & $434.6 \pm 62.7$ & 0.36 & right_subiculum & $444.9 \pm 65.9$ & $445.4 \pm 68.2$ & 0.837 \\
\hline left_CA1 & $608.6 \pm 88.6$ & $617.0 \pm 86.6$ & 0.074 & right_CA1 & $653.7 \pm 92.9$ & $652.8 \pm 97.4$ & 0.808 \\
\hline left_hippocampal-fissure & $173.1 \pm 27.0$ & $176.9 \pm 29.8$ & 0.358 & right_hippocampal-fissure & $199.9 \pm 44.7$ & $201.9 \pm 39.4$ & 0.711 \\
\hline left_presubiculum & $286.0 \pm 50.2$ & $279.3 \pm 46.7$ & 0.088 & right_presubiculum & $263.2 \pm 41.7$ & $259.2 \pm 43.7$ & 0.314 \\
\hline left_parasubiculum & $40.3 \pm 12.1$ & $40.3 \pm 10.3$ & 0.984 & right_parasubiculum & $43.2 \pm 8.8$ & $42.7 \pm 9.5$ & 0.505 \\
\hline left_molecular_layer_HP & $571.1 \pm 64.3$ & $578.0 \pm 63.7$ & 0.046 & right_molecular_layer_HP & $604.8 \pm 64.8$ & $608.2 \pm 71.3$ & 0.347 \\
\hline left_GC-ML-DG & $307.6 \pm 40.3$ & $313.2 \pm 38.7$ & 0.021 & right_GC-ML-DG & $338.2 \pm 37.8$ & $340.1 \pm 40.4$ & 0.495 \\
\hline left_CA3 & $204.3 \pm 36.4$ & $211.5 \pm 36.1$ & 0.016 & right_CA3 & $232.1 \pm 33.2$ & $235.3 \pm 35.5$ & 0.059 \\
\hline left_CA4 & $273.1 \pm 37.8$ & $277.4 \pm 34.6$ & 0.1 & right_CA4 & $299.0 \pm 34.9$ & $301.3 \pm 37.0$ & 0.34 \\
\hline left_fimbria & $84.6 \pm 16.9$ & $88.5 \pm 18.1$ & 0.135 & right_fimbria & $78.9 \pm 23.1$ & $79.2 \pm 23.5$ & 0.892 \\
\hline left_HATA & $49.5 \pm 10.4$ & $51.1 \pm 10.2$ & 0.099 & right_HATA & $55.2 \pm 9.5$ & $55.8 \pm 9.5$ & 0.308 \\
\hline left_Whole_hippocampus & $3379.0 \pm 381.1$ & $3400.5 \pm 376.8$ & 0.131 & right_Whole_hippocampus & $3578.3 \pm 421.7$ & $3580.2 \pm 444.0$ & 0.916 \\
\hline
\end{tabular}

\subsection{Change in the HAMD Score and in the Volume of the DG and CA3 Region}

There was no correlation between the change in the HAMD score and the volume increases in the molecular layer of the left hippocampus, the left GC-DG, the left CA3 regions (Figure 4). 
(a)

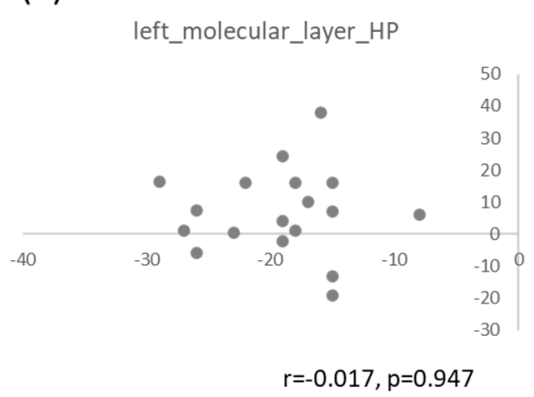

(c)

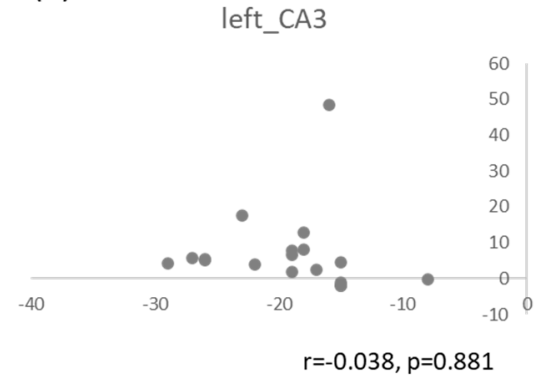

(b)

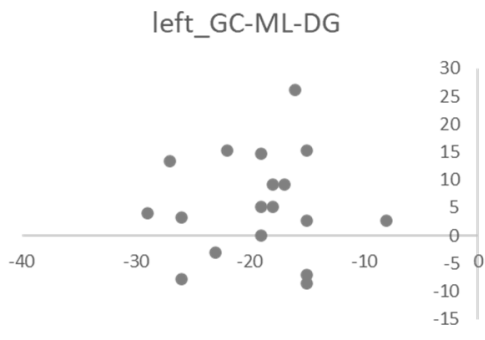

$r=0.035, p=0.892$

(d)

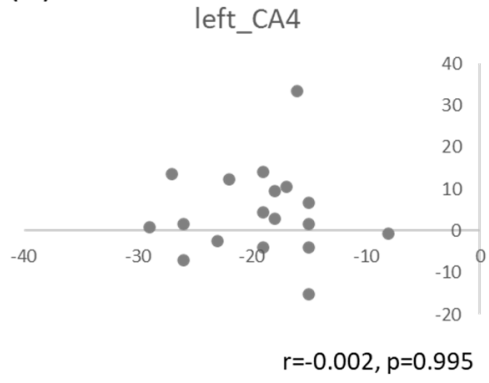

Figure 4. Difference in the HAMD score and in the volume of the left molecular layer (a), left GC-ML-DG (b), left CA3 (c), and left CA4 (d). X-axis shows the difference of the HAMD score baseline and 6 months; Y-axis shows the difference of volume $\left(\mathrm{mm}^{3}\right)$ at baseline and 6 months.

\section{Discussion}

We recruited first-episode, drug-naïve MDD patients and subsequently followed them for at least 6 months. All participants had undergone baseline MRI before starting any treatments, including pharmacotherapy. The volumes of the left cornu Ammonis (CA) 3, the left CG-DG and the whole hippocampus were increased in the MDD patients who responded to antidepressants and were subsequently in continuous remission. However, the volumes of the subfields and the whole hippocampus were not correlated to the HAMD score. The reason for this lack of correlation remains unknown. The weakest point of the present study is the lack of the normal controls and MDD patients who were not in continuous remission. Future studies should consider investigating the correlation using only MDD patients who did not undergo remission due to the negative results.

Brain imaging studies of the hippocampus in patients and stress-induced animal models with either depression or anxiety disorders indicate a remarkable reduction in hippocampal region volume and the number of dendritic spines $[13,14]$. Potentially underlying these structural anomalies, chronic stress has been shown to have detrimental effects on hippocampal neurogenesis and neuroplasticity in these individuals $[15,16]$, consequently leading to cognitive and emotional symptoms of depression and anxiety. The hippocampus is not a uniform structure and consists of several subfields, such as CA (1-4) and the DG, which includes a GCL and an ML. It is known that cellular and molecular mechanisms associated with MDD may be localized to specific hippocampal subfields. Thus, it is necessary to investigate the link between the in vivo hippocampal subfield volumes and MDD. Hippocampal subfields CA (1-3) are reduced by experimental stress in animal studies [17], which is consistent with human behavioral findings of the preferential impact of early-life maltreatment stress, particularly in high-risk patients [18]. The sub-granular zone of the dentate gyrus is only source of neurogenesis in the hippocampus [19]. Thus, the finding of an increase in the volume of these regions observed after remission and subsequent recovery in MDD patients is not a contradiction. The treatment with fluoxetine, a selective serotonin reuptake inhibitor promotes the hippocampal neurogenesis in rodents [20]. Based on the postmortem study, dentate granule cell number and dentate gyrus size 
in medicated patients with depression are larger than those in nonmedicated patient [21]. SSRIs, lithium, and electroconvulsive therapy produce larger increases in hippocampus volume in treated depressed patients than in nontreated patients [22,23]. Huang et al. reported hippocampal subfields has revealed larger dentate gyri in medicated depressed patients [24]. Although the mechanisms of the neurogenesis remain unknown, glycogen synthase kinase- $3 \beta / \beta$-catenin signaling might be involved in the mechanism of how antidepressants might influence hippocampal neurogenesis [25]. Recently, it has been reported that Tropomyosin receptor kinase B-dependent neuronal differentiation is involved in the sustained antidepressant effects of ketamine, which has potent antidepressive efficacy [26]. Nevertheless, there is no adequate evidence to establish that hippocampal neurogenesis is necessary for the antidepressant's efficacy $[27,28]$. The volumes of the bilateral CA1, bilateral CA4, left CA2/3, bilateral GCL, and bilateral ML were decreased in medicated MDD patients compared with healthy subjects [29]. The volumes of GC-DG and CA (1-3) were also decreased in unmedicated MDD patients compared with healthy controls [24]. On the other hand, Brown et al. [30] reported that there were no significant differences between MDD patients and healthy subjects in hippocampal subfield volume. Recently, we also reported that the volumes of all hippocampal subfields did not significantly differ between MDD patients and healthy controls [31]. Taken together, it remains controversial whether a significant difference exists in hippocampal subfield volume between MDD patients and healthy subjects.

FreeSurfer v6.0 was used for image processing. For all scans, "recon-all" and Longitudinal Processing [32,33] were performed first. After Longitudinal Processing, brain structure volumes were calculated based on Aseg segmentation. In addition, we calculated hippocampal subfield volumes using longitudinal segmentation [24,34]. The motivation behind the use of Longitudinal Processing was to generate topologically equivalent surface meshes for any volumes under comparison. The surface mesh generated from the unbiased within-subject template was used for repositioning of the surface mesh relative to each volume. The repositioning procedure provided surfaces with the same geometry. Therefore, longitudinal processing may provide a more accurate estimate of differences $[32,33,35]$.

Several limitations exist in the present study. First, this study has a small sample size, which was heterogeneous. Second, pharmacological treatment regulated. Third, we could not compare the difference in volume change between the two groups referring to single episode vs. recurrent/multiple episodes in the present study because of the few subjects in recurrent/multiple episodes. Fourth, we included neither a control group nor a group that did not undergo remission. Therefore, we should perform further studies considering the above points. We are now performing new project comparing the hippocampal volume of MDD patients in first episode and recurrent episodes treated with SSRIs and SNRIs with a larger sample.

In conclusion, an increase in the volume of CA3 and CG-DC of the only left, but not right hippocampus was observed in drug-naive MDD patients who subsequently underwent remission for at least 6 months with antidepressant use.

\section{Material and Methods}

\subsection{Ethics Statement}

The study protocol was approved by the Ethics Committee (approval number: H25-13, 8 May 2013) of the University of Occupational and Environmental Health, Japan. Written informed consent was obtained from all subjects who participated in this study. Informed consent was obtained from each patient in accordance with the Declaration of Helsinki.

\subsection{Participants}

The patients with MDD were recruited from the University hospital of University of Occupational and Environmental Health, Japan. The subjects in the present study partially overlapped with those in our recently published study. Eighteen patients with major depressive disorder were additionally 
enrolled in the present study. The MDD patients were recruited from March 2009 to January 2017. All patients were diagnosed by using the full Structured Clinical Interview from the Diagnostic and Statistical Manual for Mental Disorders, Fourth Edition, Text revision, Research Version. The severity of the depressive state was evaluated using the 17-item Hamilton Rating Scale for Depression (HAMD). Patients who met the following criteria were enrolled in the study: (a) a diagnosis of MDD, (b) a HAMD score of $\geq 14$, (c) drug-naïveté MDD, and (d) response to antidepressant treatment (a $50 \%$ or more reduction in the HAMD score at week 8 from week 0 ). The exclusion criteria were as follows: (a) a history of neurological disease and/or the presence of psychiatric disorders on either Axis I (schizophrenia, other affective disorders, etc.) or Axis II (personality disorders, mental retardation, etc.), (b) the presence of comorbid substance use disorders, and (c) lack of a second MRI. Eighteen right-handed drug-naïve patients with MDD were included in this study. The clinical and demographic characteristics of the patients are summarized in Table 2. Patients took one of several classes of antidepressants, including selective serotonin reuptake inhibitors, i.e., escitalopram $(n=2$, maximum dose: $20 \mathrm{mg} /$ day $)$, sertraline $(n=3$, maximum dose: $150 \mathrm{mg} /$ day $)$, paroxetine $(n=5$, maximum dose: $40 \mathrm{mg} /$ day), and fluvoxamine ( $n=3$, maximum dose: $200 \mathrm{mg} /$ day), and serotonin and norepinephrine reuptake inhibitors, i.e., duloxetine $(n=3$, maximum dose: $60 \mathrm{mg} /$ day $)$, and mirtazapine $(n=2$, maximum dose: $45 \mathrm{mg} /$ day) at least 6 months or more.

Table 2. The characteristics of patients, the HAMD score, and dose of antidepressants.

\begin{tabular}{cc}
\hline $\mathbf{N}$ & $\mathbf{1 8}$ \\
\hline Age & $44.4 \pm 13.8$ \\
\hline Gender(Male/Female) & $10 / 8$ \\
\hline Episode(First/Recurrent) & $12 / 6$ \\
\hline HAM-D T0 & $22.5 \pm 4.99$ \\
\hline HAM-D 8weeks & $5.4 \pm 2.6$ \\
\hline HAM-D 6months & $3.2 \pm 1.7$ \\
\hline dose at 8 weeks (imipramine equivalent) & $188 \pm 105.2$ \\
\hline
\end{tabular}

All participants underwent T1-weighted structural MRI and were treated with antidepressants for 8 weeks. We defined patients whose HAM-D scores were $<8$ points or less as being in remission. We compared the volume of the hippocampus, including its subfields, in patients in remission at baseline to the volume at 6 months (Table 2).

\subsection{MRI Acquisition}

All participants underwent T1-weighted structural MRI at baseline and at 6 months after starting antidepressant therapy. The MRI data were obtained using a 3 T MR System (Signa EXCITE 3T; GE Healthcare, Wankesha, WI, USA) with an 8-channel brain phased-array coil. The original T1 images were acquired using a 3D fast-spoiled gradient recalled acquisition in the steady state. The acquisition parameters were as follows: repetition time in $\mathrm{ms} / \mathrm{echo}$ time in $\mathrm{ms} /$ inversion time in $\mathrm{ms}=10 / 4.1 / 700$; flip angle $=10$; field-of-view $=24 \mathrm{~cm}$; section thickness $=1.2 \mathrm{~mm}$, and resolution $=0.9 \times 0.9 \times 1.2 \mathrm{~mm}^{3}$. All the images were corrected for image distortion resulting from gradient nonlinearity using the Grad Warp software program and from intensity inhomogeneity using the "N3" function [36].

\subsection{Image Processing}

FreeSurfer v6.0 (http://surfer.nmr.mgh.harvard.edu/) was used for image processing. For all scans, "recon-all" and Longitudinal Processing [32,33] were performed first. For each subject, templates for one scanning session were generated from images acquired at baseline and 6 months later. After Longitudinal Processing, brain structure volumes were calculated based on Aseg segmentation. 
In addition, we calculated hippocampal subfield volumes using longitudinal segmentation [24,34]. The motivation behind the use of Longitudinal Processing was to generate topologically equivalent surface meshes for any volumes under comparison. The surface mesh generated from the unbiased, within-subject template was used for repositioning of the surface mesh relative to each volume. The repositioning procedure provided surfaces with the same geometry. Therefore, Longitudinal Processing may provide a more accurate estimate of differences among subjects [32,33,35]. Although the results provided by Longitudinal Processing may not be generalized to those provided with a conventional stream, the same differences can be detected by pooling measurements across a large population to average the processing bias [35].

\subsection{Statistical Analysis}

We used paired t-rests to compare the change in hippocampal subfield volume between baseline and after 6 months. We calculated Pearson's correlation coefficients between the change in the HAMD score and the change in hippocampal subfield volume. We regarded values of $p<0.05$ (two tailed) as a statistically significant difference.

Author Contributions: A.K. designed the study, collected the clinical data, performed the statistical analyses, wrote the first draft and managed the literature searches. R.Y. revised the study protocol and wrote the final manuscript. Y.K., and A.I. checked the final manuscript. S.K. and K.W. helped with the statistical analyses. R.I. collected the clinical data. L.N. and Y.O. collected the clinical data. All authors took part in either drafting the article or revising it critically for important intellectual content and approved the final manuscript.

Funding: This research received no external funding.

Acknowledgments: The authors thank Kenji Hayashi for informing each patient about the clinical data. The authors also thank Katherine L Narr (Ahmanson-Lovelace Brain Mapping Center, Department of Neurology, and Department of Psychiatry and Biobehavioral University of California Los Angeles, Los Angeles, CA, USA) for her helpful comments and English correction of the manuscript.

Conflicts of Interest: The authors declare no conflict of interest.

\section{References}

1. Dusi, N.; Barlati, S.; Vita, A.; Brambilla, P. Brain Structural Effects of Antidepressant Treatment in Major Depression. Curr. Neuropharmacol. 2015, 13, 458-465. [CrossRef] [PubMed]

2. Bennet, M.R. The prefrontal-limbic network in depression: A core pathology of synapse regression. Prog. Neurobiol. 2011, 93, 457-467. [CrossRef] [PubMed]

3. Sapolsky, R.M. Glucocorticoids and hippocampal atrophy in neuropsychiatric disorders. Arch. Gen. Psychiatry 2000, 57, 925-935. [CrossRef] [PubMed]

4. Schmaal, L.; Veltman, D.J.; Van Erp, T.G.; Samann, P.G.; Frodl, T.; Jahanshad, N.; Loehrer, E.; Tiemeier, H.; Hofman, A.; Niessen, W.J.; et al. Subcortical brain alterations in major depressive disorder: Findings from the ENIGMA major depressive disorder working group. Mol. Psychiatry 2016, 21, 806-812. [CrossRef] [PubMed]

5. Arnone, D.; McIntosh, A.M.; Ebmeier, K.P.; Munafo, M.R.; Anderson, I.M. Magnetic resonance imaging studies in unipolar depression: Systematic review and meta-regression analyses. Eur. Neuropsychopharmacol. 2012, 22, 1-16. [CrossRef] [PubMed]

6. Campbell, S.; Marriott, M.; Nahmias, C.; MacQueen, G.M. Lower hippocampal volume in patients suffering from depression: A meta-analysis. Am. J. Psychiatry 2004, 161, 598-607. [CrossRef]

7. Small, S.A.; Schobel, S.A.; Buxton, R.B.; Witter, M.P.; Barnes, C.A. A pathophysiological framework of hippocampal dysfunction in ageing and disease. Nat. Rev. Neurosci. 2011, 12, 585-601. [CrossRef]

8. Hibar, D.P.; Adams, H.H.H.; Jahanshad, N.; Chauhan, G.; Stein, J.L.; Hofer, E.; Renteria, M.E.; Bis, J.C.; Arias-Vasquez, A.; Ikram, M.K.; et al. Novel genetic loci associated with hippocampal volume. Nat. Commun. 2017, 8, 13624. [CrossRef]

9. Vakili, K.; Pillay, S.S.; Lafer, B.; Fava, M.; Renshaw, P.F.; Bonello-Cintron, C.M.; Yurgelun-Todd, D.A. Hippocampal volume in primary unipolar major depression: A magnetic resonance imaging study. Biol. Psychiatry 2000, 47, 1087-1090. [CrossRef] 
10. Godlewska, B.R.; Hasselmann, H.W.; Igoumenou, A.; Norbury, R.; Cowen, P.J. Short-term escitalopram treatment and hippocampal volume. Psychopharmacology 2014, 231, 4579-4581. [CrossRef]

11. Maller, J.J.; Broadhouse, K.; Rush, A.J.; Gordon, E.; Koslow, S.; Grieve, S.M. Increased hippocampal tail volume predicts depression status and remission to anti-depressant medications in major depression. Mol. Psychiatry 2018, 23, 1737-1744. [CrossRef] [PubMed]

12. Cao, B.; Luo, Q.; Fu, Y.; Du, L.; Qiu, T.; Yang, X.; Chen, X.; Chen, Q.; Soares, J.C.; Cho, R.Y.; et al. Predicting individual responses to the electroconvulsive therapy with hippocampal subfield volumes in major depression disorder. Sci. Rep. 2018, 8, 5434. [CrossRef] [PubMed]

13. Van Tol, M.J.; Van der Wee, N.J.; Van den Heuvel, O.A.; Nielen, M.M.; Demenescu, L.R.; Aleman, A.; Renken, R.; Van Buchem, M.A.; Zitman, F.G.; Veltman, D.J. Regional brain volume in depression and anxiety disorders. Arch. Gen. Psychiatry 2010, 67, 1002-1011. [CrossRef] [PubMed]

14. McEwen, B.S.; Eiland, L.; Hunter, R.G.; Miller, M.M. Stress and anxiety: Structural plasticity and epigenetic regulation as a consequence of stress. Neuropharmacology 2012, 62, 3-12. [CrossRef] [PubMed]

15. Pittenger, C.; Duman, R.S. Stress, depression, and neuroplasticity: A convergence of mechanisms. Neuropsychopharmacology 2008, 33, 88-109. [CrossRef] [PubMed]

16. Bannerman, D.M.; Sprengel, R.; Sanderson, D.J.; McHugh, S.B.; Rawlins, J.N.; Monyer, H.; Seeburg, P.H. Hippocampal synaptic plasticity, spatial memory and anxiety. Nat. Rev. Neurosci. 2014, 15, 181-192. [CrossRef]

17. Sapolsky, R.M. Atrophy of the hippocampus in posttraumatic stress disorder: How and when? Hippocampus 2001, 11, 90-91. [CrossRef]

18. Morey, R.A.; Haswell, C.C.; Hooper, S.R.; De Bellis, M.D. Amygdala, hippocampus, and ventral medial prefrontal cortex volumes differ in maltreated youth with and without chronic posttraumatic stress disorder. Neuropsychopharmacology 2016, 41, 791-801. [CrossRef]

19. Jahn, H.M.; Bergami, M. Critical periods regulating the circuit integration of adult-born hippocampal neurons. Cell Tissue Res. 2018, 371, 23-32. [CrossRef]

20. Perera, T.D.; Coplan, J.D.; Lisanby, S.H.; Lipria, C.M.; Arif, M.; Caprio, C.; Spitzer, G.; Santarelli, L.; Scharf, B.; Hen, R.; et al. Antidepressant-induced neurogenesis in the hippocampus of adult nonhuman primates. J. Neurosci. 2007, 27, 4894-4901. [CrossRef]

21. Boldrini, M.; Butt, T.H.; Santiago, A.N.; Tamir, H.; Dwork, A.J.; Rosoklijia, G.B.; Arango, V.; Hen, R.; Mann, J.J. Benzodiazepines and the potential trophic effect of antidepressants on dentate gyrus cells in mood disorders. Int. J. Neuropsychopharmacol. 2014, 17, 1923-1933. [CrossRef]

22. Hallahan, B.; Newell, J.; Soares, J.C.; Brambilla, P.; Strakowski, S.M.; Fleck, D.E.; Kieseppa, T.; Altshuler, L.L.; Frnito, A.; Maihi, G.S.; et al. Structural magnetic resonance imaging in bipolar disorder: An international collaborative mega-analysis of individual adult patient data. Biol. Psychiatry 2011, 69, 326-335. [CrossRef] [PubMed]

23. Tendolkar, I.; van Beek, M.; van Oostrom, I.; Mulder, M.; Janzing, J.; Voshaar, R.O.; van Eijndoven, P. Electroconvulsive therapy increases hippocampal and amygdala volume in therapy refractory depression: A Longitudinal Pilot Study. Psychiatry Res. 2013, 214, 197-203. [CrossRef] [PubMed]

24. Huang, Y.; Coupland, N.J.; Lebel, R.M.; Carter, R.; Seres, P.; Wilman, A.H.; Malykhin, N.V. Structural changes in hippocampal subfields in major depressive disorder: A high-field magnetic resonance imaging study. Biol. Psychiatry 2013, 74, 62-68. [CrossRef] [PubMed]

25. Hui, J.; Zhang, J.; Kim, H.; Tong, C.; Ying, Q.; Li, Z.; Mao, X.; Shi, G.; Yan, J.; Zhang, Z.; et al. Fluoxetine regulates neurogenesis in vitro through modulation of GSK-3 $\beta / \beta$-catenin signaling. Int. J. Neuropsychopharmacol. 2014, 18. [CrossRef]

26. Ma, Z.; Zang, T.; Birnbaum, S.G.; Wang, Z.; Johnson, J.E.; Zhang, C.L.; Parada, L.F. TrkB dependent adult hippocampal progenitor differentiation mediates sustained ketamine antidepressant response. Nat. Commun. 2017, 8, 1668. [CrossRef]

27. Sahay, A.; Hen, R. Adult hippocampal neurogenesis in depression. Nat. Neurosci. 2007, 10, 1110-1115. [CrossRef]

28. Tunc-Ozcan, E.; Peng, C.Y.; Zhu, Y.; Dunlop, S.R.; Contractor, A.; Kessler, J.A. Activating newborn neurons suppresses depression and anxiety-like behaviors. Nat. Commun. 2019, 21, 3768. [CrossRef]

29. Han, K.M.; Kim, A.; Kang, W.; Kang, Y.; Kang, J.; Won, E.; Tae, W.S.; Ham, B.J. Hippocampal subfield volumes in major depressive disorder and bipolar disorder. Eur. Psychiatry 2019, 57, 70-77. [CrossRef] 
30. Brown, S.S.G.; Rutland, J.W.; Verma, G.; Feldman, R.E.; Alper, J.; Schneider, M.; Delman, B.N.; Murrough, J.M.; Balchandani, P. Structural MRI at 7T reveals amygdala nuclei and hippocampal subfield volumetric association with major depressive disorder symptom severity. Sci. Rep. 2019, 9, 10166. [CrossRef]

31. Otsuka, Y.; Kakeda, S.; Sugimoto, K.; Katsuki, A.; Nguyen, L.H.; Igata, R.; Watanabe, K.; Ueda, I.; Kishi, T.; Iwata, N.; et al. COMT polymorphism regulates the hippocampal subfield volumes in first-episode, drug-naive patients with major depressive disorder. Neuropsychiatr. Dis. Treat. 2019, 15, 1537-1545. [CrossRef] [PubMed]

32. Fischl, B.; Dale, A.M. Measuring the thickness of the human cerebral cortex from magnetic resonance images. Proc. Natl. Acad. Sci. USA 2000, 97, 11050-11055. [CrossRef] [PubMed]

33. Van Leemput, K.; Bakkour, A.; Benner, T.; Wiggins, G.; Wald, L.L.; Augustinack, J.; Dickerson, B.C.; Golland, P.; Fischl, B. Automated segmentation of hippocampal subfields from ultra-high resolution in vivo MRI. Hippocampus 2009, 19, 549-557. [CrossRef] [PubMed]

34. Han, K.M.; Won, E.; Sim, Y.; Tae, W.S. Hippocampal subfield analysis in medication-naive female patients with major depressive disorder. J. Affect. Disord. 2016, 194, 21-29. [CrossRef] [PubMed]

35. Iglesias, J.E.; Augustinack, J.C.; Nguyen, K.; Player, C.M.; Player, A.; Wright, M.; Roy, N.; Frosch, M.P.; McKee, A.C.; Wald, L.L.; et al. A computational atlas of the hippocampal formation using ex vivo, ultra-high resolution MRI: Application to adaptive segmentation of in vivo MRI. NeuroImage 2015, 115, 117-137. [CrossRef]

36. Sled, J.G.; Zijdenbos, A.P.; Evans, A.C. A nonparametric method for automatic correction of intensity nonuniformity in MRI data. Ieee Trans. Med. Imaging 1998, 17, 87-97. [CrossRef]

(C) 2020 by the authors. Licensee MDPI, Basel, Switzerland. This article is an open access article distributed under the terms and conditions of the Creative Commons Attribution (CC BY) license (http://creativecommons.org/licenses/by/4.0/). 